\title{
A DSS Framework for Advanced Traffic Signal Control System Investment Planning
}

\author{
Houng Y. Soo and Dusan Teodorovic, \\ Virginia Polytechnic Institute and State University \\ John Collura, University of Massachusetts
}

\begin{abstract}
This article presents ongoing research on the initial development of a decision support system (DSS) framework for integrated emergency vehicle preemption and transit priority system investment planning. A conceptual intelligent DSS framework provides a holistic framework to perform analytical assessments of integrated emergency vehicle preemption and transit priority systems. Three analytical tools are presented for incorporation into future DSS design: the first addresses the potential impact of transit travel time reduction on transit operating costs; the second addresses the potential impact of reduced emergency vehicle crashes at signalized intersections on fire and rescue operating costs; and the third integrates fuzzy sets concepts and multiattribute decision-making methods to rank order transit signal priority strategy alternatives at the intersection level.
\end{abstract}

\section{Introduction}

Advances in microprocessor and communications technologies are making it possible for current traffic signal controllers and vehicle detection technology to accommodate both emergency vehicle preemption and transit priority strategies 
as part of an integrated system. However, investment planning for an integrated emergency vehicle preemption and transit signal priority system is not a trivial task. Two distinct service providers, fire and rescue providers and transit operators, with separate operational functions, resources, objectives, and constituents are involved. In addition, a variety of institutional and local concerns-ranging from the identification of the important stakeholders, to the assessment of emergency vehicle preemption and transit signal priority system impacts, to performing economic analysis to determine efficiency and effectiveness of an investment from a systems perspective, must be taken into account.

Currently, transportation planners and managers interested in deploying these advanced traffic signal control systems do not have an evaluation approach or a set of common performance metrics to make informed planning decisions. Planners and managers need a structured analytical approach to use as part of their investment planning process.

This need may be met by a decision support system that (1) is designed to assess simultaneously the impacts of integrated emergency vehicle preemption and transit signal priority systems for investment purposes, and (2) has the ability to process both quantitative and qualitative data at varying degrees of precision.

This article presents ongoing research on the development of a DSS framework for advanced traffic signal control system investment planning. This study builds and expands on previous research on economic evaluation frameworks, evaluation of preferential treatments of emergency vehicle preemption and transit vehicle priority at signalized intersections, emergency vehicle crash characteristics, and transit travel time reduction.

\section{Literature Review}

Emergency vehicle preemption and transit signal priority systems are similar from a systems perspective, in that they both consist of a vehicle detection system, a communications system, and a traffic signal control system. Together, as components of a system, they have the capability to provide preferential treatment to both emergency vehicles and qualified transit vehicles. Research suggests that both emergency and transit vehicles would benefit from preferential treatment strategies with minimal impact on other users (Collura, Rakha, and Gifford 2003).

Research to date has addressed the individual impacts of emergency vehicle preemption and transit priority systems from an operational perspective. Fire and res- 
cue providers are interested in emergency vehicle preemption to reduce response time, increase safety, and reduce emergency vehicle crashes at signalized intersections (Bullock, Morales, and Sanderson 1999). Transit operators are interested in transit signal priority to reduce transit travel time, improve schedule reliability, and reduce operating expenses (Chang et al. 2002). Evaluation frameworks, performance measures, and guidelines have been developed that are specific to either emergency vehicle preemption or transit vehicle priority and oriented toward the assessment of their specific operational performance characteristics. In addition, results from field measurements and simulations for both emergency vehicle preemption and transit signal priority are often imprecise in nature, making it difficult to benchmark performance characteristics accurately.

The travel impacts of an advanced traffic signal control system capable of integrated emergency vehicle preemption and transit signal priority operations and their respective stakeholders are shown in Table 1. The distribution of the 10 travel impacts illustrates the complex and interdependent nature of integrated emergency vehicle preemption and transit signal priority systems. The stakeholders

\section{Table 1. Advanced Traffic Signal Control System Travel Impact Distribution}

\begin{tabular}{|c|c|c|c|}
\hline $\begin{array}{l}\text { Preferential } \\
\text { Treatment }\end{array}$ & Objective & Travel Impact & Stakeholders \\
\hline \multirow{6}{*}{$\begin{array}{l}\text { Transit Signal } \\
\text { Priority }\end{array}$} & \multirow{3}{*}{ Reduces transit travel time } & Reduces transit O\&M costs & Transit service provider \\
\hline & & $\begin{array}{l}\text { Reduces travel time for } \\
\text { passengers }\end{array}$ & Transit passengers \\
\hline & & $\begin{array}{l}\text { Reduces passenger non-travel } \\
\text { time }\end{array}$ & Transit passengers \\
\hline & $\begin{array}{l}\text { Increases bus service } \\
\text { reliability }\end{array}$ & $\begin{array}{l}\text { Reduces transit passenger non- } \\
\text { travel time }\end{array}$ & Transit passengers \\
\hline & $\begin{array}{l}\text { Reduces other vehicle travel } \\
\text { time on arterial }\end{array}$ & $\begin{array}{l}\text { Reduces travel time for others } \\
\text { on bus route }\end{array}$ & Motorist \\
\hline & $\begin{array}{l}\text { Increases other vehicle travel } \\
\text { time on side streets }\end{array}$ & $\begin{array}{l}\text { Increases travel time on side } \\
\text { streets }\end{array}$ & Motorist \\
\hline \multirow{4}{*}{$\begin{array}{l}\text { Emergency } \\
\text { Vehicle } \\
\text { Preemption }\end{array}$} & Reduces EV travel time & $\begin{array}{l}\text { Saves lives } \\
\text { Reduces injury } \\
\text { Reduces fire damage }\end{array}$ & $\begin{array}{l}\text { General public } \\
\text { (elected officials) }\end{array}$ \\
\hline & Reduces EV crashes & $\begin{array}{l}\text { Reduces accident costs at } \\
\text { signalized intersections }\end{array}$ & Fire and rescue provider \\
\hline & $\begin{array}{l}\text { Increases delays to other } \\
\text { vehicles }\end{array}$ & $\begin{array}{l}\text { Increases travel time for other } \\
\text { drivers and passengers }\end{array}$ & Motorist \\
\hline & Increases delay to transit & $\begin{array}{l}\text { Increases travel time for transit } \\
\text { passengers }\end{array}$ & Transit passengers \\
\hline
\end{tabular}


are the recipients of these positive and negative impacts. Planners and managers must consider input from elected officials, the general public, transit passengers, nontransit users, emergency service providers, and transit operators in their investment decisions. This requires coordination among the major stakeholders to address institutional, technical, and financial issues. Traditionally, each service provider has planned and costed their version of the system separately. Table 1 suggests that the benefits from reduced operating costs to the two service providers (transit and fire and rescue) may be eclipsed by the impact to the general public, transit riders, and motorists (Soo et al. 2004).

Previous research has produced useful information on key transit performance characteristics such as transit travel time reductions (Chang 2002), schedule reliability (Chang et al. 2002), nontransit delay (Ngan 2003), and stakeholder concerns (Noyce 1996; Gifford, Pelletiere, and Collura 2001; Levin et al. 1999). Their information reinforces the uncertainty and imprecision of the available data. These results, while dependent on the method of collection as well as geometric and operational conditions, are useful in providing "order of magnitude" estimates to improve our understanding of the impacts of transit signal priority, but they do not have the precision desired for use in more systematic mathematical modeling.

Fuzzy sets theory is a convenient mathematical device for treating imprecise (uncertain, subjective, and ambiguous) data. Fuzzy sets theory has been applied in mathematical modeling of traffic and transportation processes that include traffic control, traffic assignment modeling, vehicle modeling, scheduling and dispatch modeling, cost-benefit analysis, and transportation investment planning (Teodorovic 1994).

\section{Decision Support System Development}

\section{Decision Support System Framework}

DSS is made up of computer technology solutions that can be used to support complex decision making and problem solving. A generic intelligent DSS consists of four components: database management module, model management module, knowledge management module, and user interface module. The structure of a conceptual intelligent DSS framework designed to assess the impacts of integrated emergency vehicle preemption and transit signal priority systems is shown in Figure 1. 


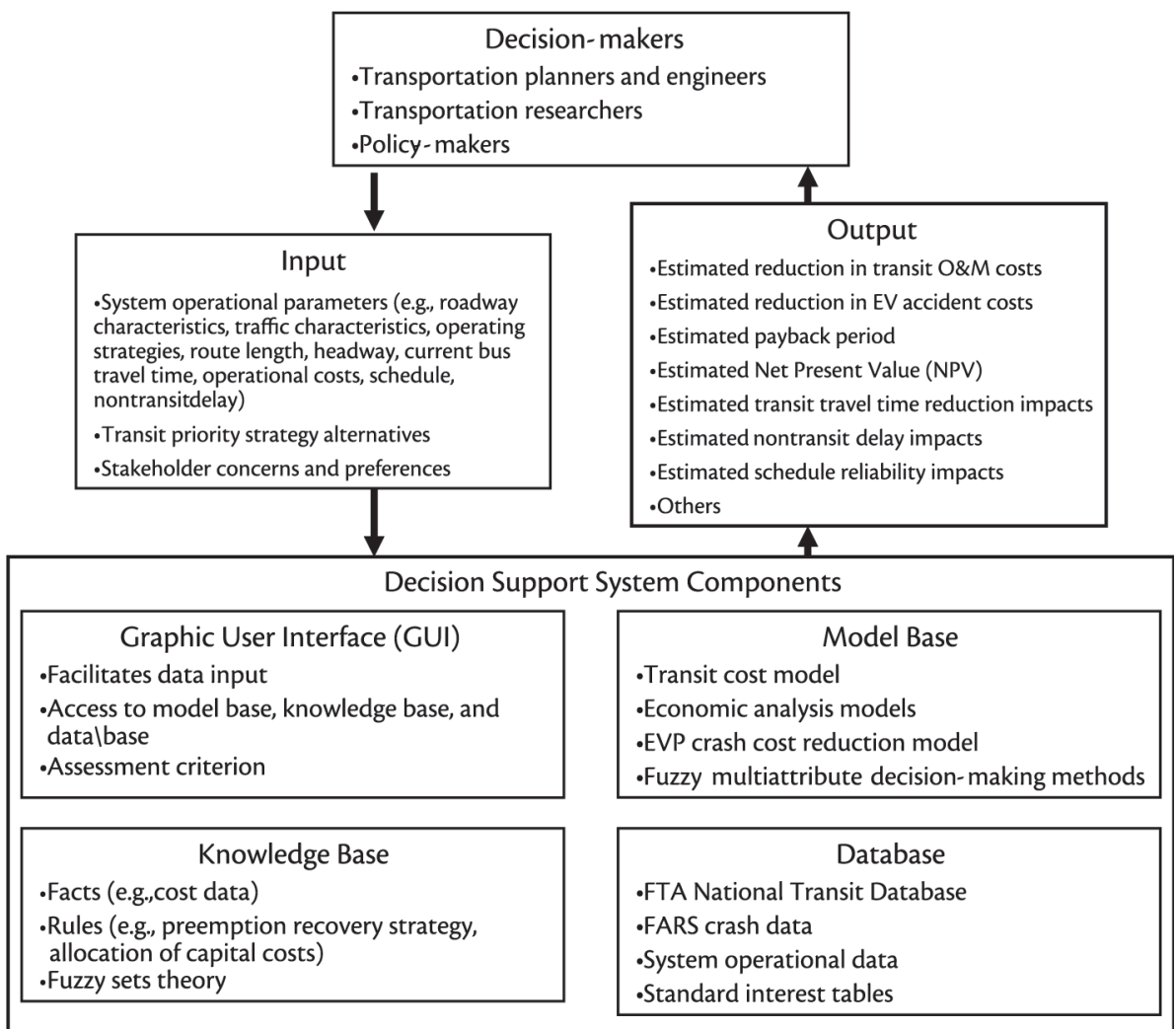

Figure 1. DSS Framework

This DSS is intended for transportation planners and engineers, transportation researchers, and policy-makers. User input would include system operational parameters (roadway characteristics, traffic characteristics, and system operational strategies), transit signal priority alternatives, and stakeholder concerns and preferences. Desired DSS output include graphic and numeric results relating to economic analysis (payback period, capital recovery period, NPV, etc.), operational performance (transit run-time reduction, schedule reliability impacts), operating cost savings, and transit signal priority strategy alternatives.

The database management module contains operational and financial data for transit operations, fire and rescue operations, accident and safety statistics, as well as system operational data. 
The model management module provides the environment for storing, retrieving, and manipulating models. It links the user to the appropriate mathematical models, optimization methods, analytical tools, and procedures to perform various types of analyses.

The knowledge base module contains problem-specific rules and facts relating to transit operations, fire and rescue operations, advanced traffic signal control systems costs, as well as the ability to use soft computing techniques. This module makes available expert knowledge to substitute human expertise for missing algorithms. The incorporation of intelligent DSS functionalities in the form of soft computing adds the ability to process both quantitative and qualitative data at varying levels of precision.

The user interface module provides the means for the user to interface with the DSS and to (1) access the database, model base, and expert knowledge base; (2) input information such as performance characteristics; (3) display and analyze data and formulate and evaluate alternative decisions; and (4) view output displays.

\section{Analytical Tools}

Research in the development of this conceptual DSS framework has generated three analytical tools that could be incorporated into the DSS. The first addresses the potential impact of transit travel time reduction due to transit signal priority on transit operating costs. The second addresses the potential impact of reduced emergency vehicle accidents on signalized intersections due to emergency vehicle preemption. The third utilizes soft computing techniques in the form of fuzzy sets theory concepts to deal with the imprecision normally associated with transit signal priority strategy alternative performance characteristics.

Transit O\&M Cost Impact. A potential impact of transit signal priority is reduced transit travel time. Transit service providers are interested because of the potential to save operating costs; transit passengers are interested because of the potential to reduce both travel time and nontravel time. In the austere public fiscal environment, both efficiency (Will society benefit from this investment?) and cost effectiveness (Can we afford to do this?) are important factors to be considered in the decision-making process. Efficiency measures the economic feasibility of an investment from a societal perspective and is an outcome of a benefit-cost analysis. It answers the question "Are the total net benefits received by society 
as a whole increased by the project?" Cost effectiveness addresses the question "Will this improvement generate enough money to pay for its development and operation?" and measures the financial feasibly of a project. Ideally, society should benefit from the deployment of an advanced traffic signal control system and the cost of deployment should be recouped directly from operating and capital cost savings (ECONWest and Parsons Brinckerhoff Quade \& Douglas 2002; Lee and Carroll 2001; Morlok, Brunn, and Blackman 1991).

Figure 2 presents a simple three-step spreadsheet model to estimate the impact of reduced transit $O \& M$ costs and whether that reduction is sufficient to warrant the investment costs. The model answers the question "Can we afford to do this investment?"

- Step 1 computes the operating cost savings based on the total transit travel time reduction.

- Step 2 computes the investment costs and annual costs associated with this deployment.

- Step 3 provides the results of several assessments: payback period analysis, capital recovery period analysis, and net present value analysis. The payback period represents the amount of time that it takes for a project to recover its initial cost ignoring the time value of money. It answers the question "How quickly can the investment be recovered based on savings in operating costs associated with the transit signal priority system?" The capital recovery period represents the amount of time it takes for a project to recover its initial cost taking into account the time value of money. Finally, net present value analysis projects the present value of future savings expected from an investment.

A system-level analysis was conducted using data collected at the Virginia Tech/ George Mason University/Virginia Department of Transportation integrated emergency vehicle preemption and transit signal priority operational field test on U.S. 1 in Northern Virginia. The results suggest that planners and managers may need to consider apportioning the investment costs of integrated emergency vehicle preemption and transit signal priority systems. Traditionally, fire and rescue service providers and transit service providers each estimated deployment costs from a myopic perspective. The notion of cost sharing among the two service providers and the municipality recognizes the interactive role of these agencies in providing quality service to the public. 

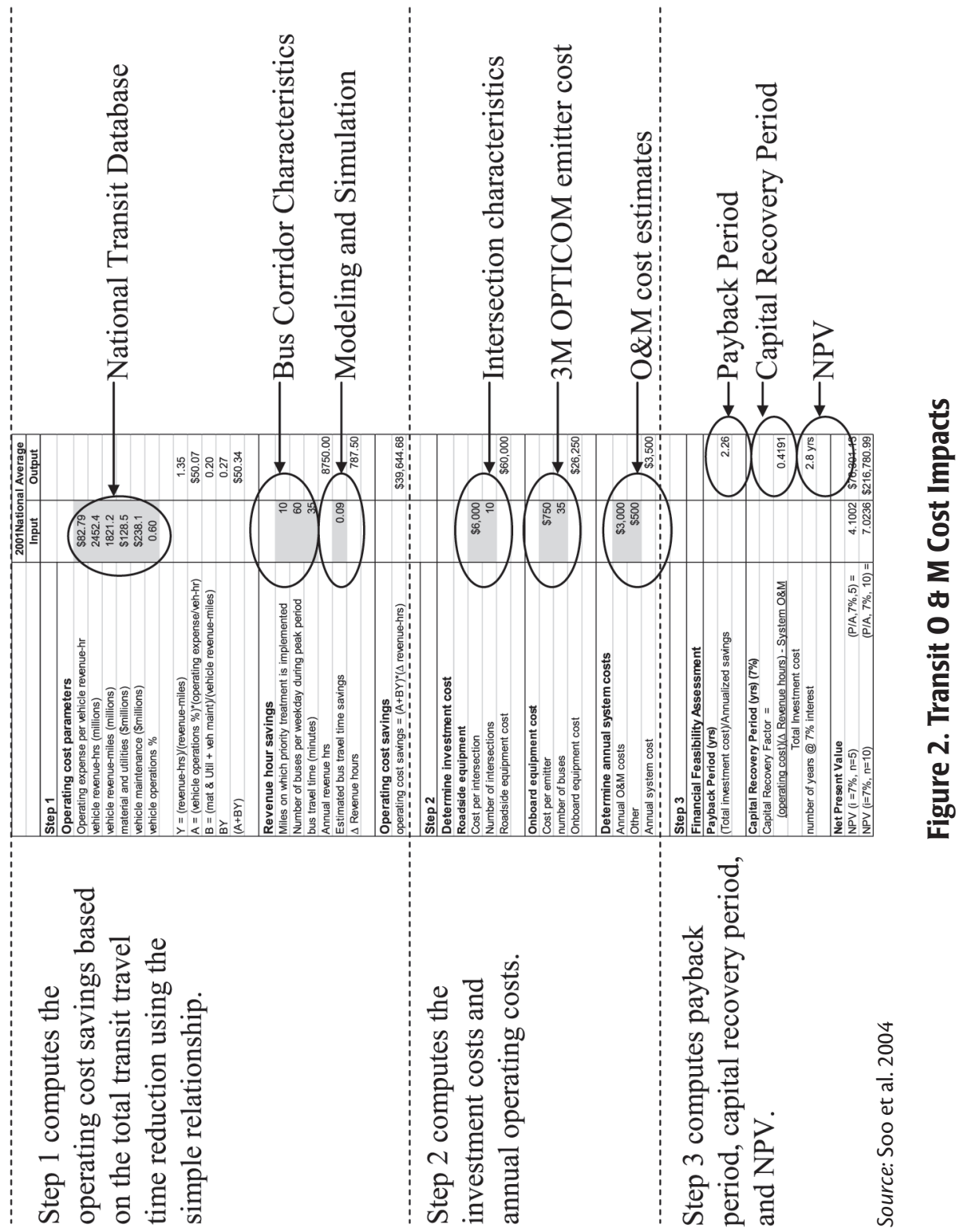
Emergency Vehicle Crash Reduction Operating Cost Impact. A potential impact of reduced emergency vehicle crashes on signalized intersections is reduced fire and rescue operating costs. Operational experience suggests that the deployment of emergency vehicle preemption may decrease the number and severity of accidents involving emergency vehicles and other vehicles at signalized intersections. Reducing emergency vehicle crashes at signalized intersections will reduce the cost to repair emergency vehicles damaged in crashes, reduce the cost of vehicle insurance, and reduce nonavailability time awaiting repairs. A simple spreadsheet model that can be used to assess average savings is presented in Figure 3. The number of emergency vehicle crashes and their distribution on signalized and nonsignalized intersections and nonintersections can be determined from fire and rescue operational data or from regional accident report databases. Historical information can also be used to estimate average repair cost.

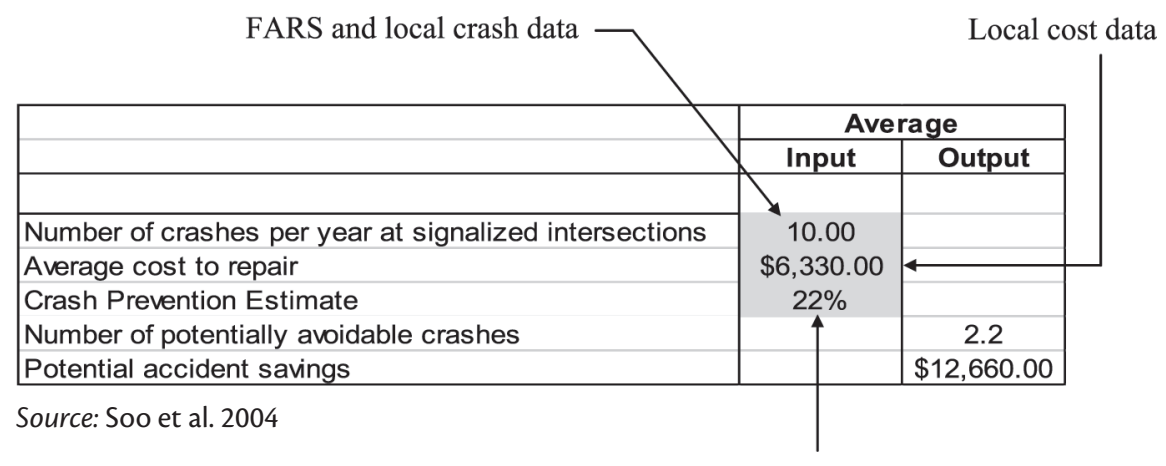

Extracted from St Paul data

Figure 3. Emergency Vehicle Crash Reduction Operating Cost Impact

The example shown in Figure 3 suggests that a 22 percent crash reduction to a fire and rescue provider with 10 signalized intersection crashes per year and an average repair cost of $\$ 6,330$, can potentially save $\$ 12,660$ in operating costs (Gkritza et al. 2004; Soo et al. 2004).

Fuzzy Multiattribute Decision Making. Determining the most preferred transit signal priority strategy alternative for an intersection is not a trivial task. Beforeand-after operational data for deployed transit signal priority systems is limited, and the available data is not standardized, is dependent on geometric and operational conditions, and is characterized by imprecision. In addition, stakeholders representing multiple constituencies (e.g., elected officials, traffic representatives, 
transit representatives, emergency service providers, transit riders, nontransit operators, community organizations, and pedestrians) often have conflicting interests that must be incorporated in the decision process.

To this end, a systematic evaluation tool using multiattribute decision-making (MADM) methods and fuzzy sets concepts was developed to quantify the expected impacts of transit travel time reductions, nontransit delays, and service reliability as they relate to alternative transit signal priority strategies with varying stakeholder preferences (Soo, Collura, and Teodorovic 2005).

Three fuzzy set concepts will be used to derive triangular fuzzy numbers for use in fuzzy MADM methods. The concept of triangular fuzzy numbers will be used to describe the impact of transit signal priority strategy alternatives on transit travel time reduction; linguistic variables will be used to describe their impact on nontransit delay; and the intersection of fuzzy sets will be use to uniquely measure the impact of the four alternatives on schedule reliability. Linguistic variables will also be used to determine stakeholder preference-based weighting for the three criteria.

Linguistic variables are used when criteria cannot be quantified. Values of linguistic variables are words such as "not important," "important," and "very important." Figure 4 presents the membership function of fuzzy sets "not important," "important," and "very important." Their corresponding triangular fuzzy numbers are $(0,0,5),(0,5,10)$, and $(5,10,10)$, respectively.

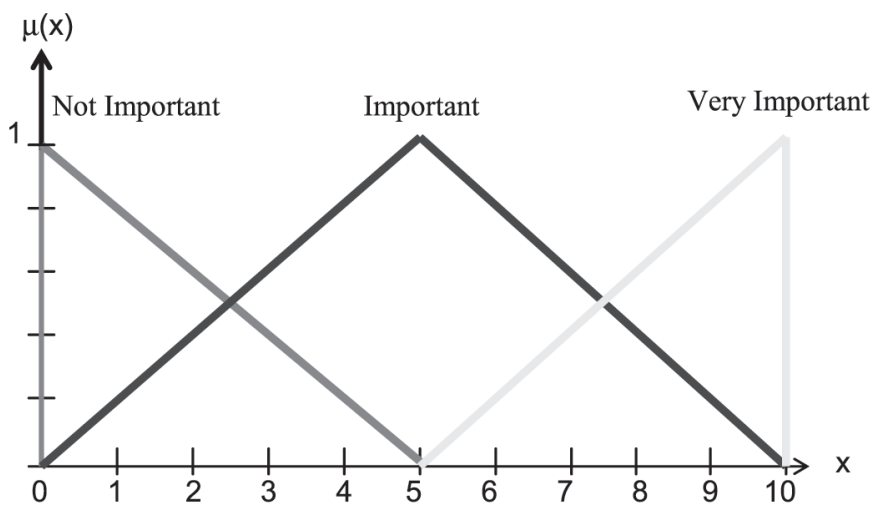

Figure 4. Membership Function of Fuzzy Sets "Not Important," "Important," “Very Important" 
The resultant decision matrix can be ranked using standard fuzzy MADM methods such as the weighted sum method (WSM) and the Technique for Order Preference by Similarity to Ideal Solutions (TOPSIS) (Chen and Hwang 1992).

Fuzzifying Transit Travel Time Reduction Performance Data. The impact of various transit signal priority strategy alternatives on transit travel time reduction is a key criterion. Transit travel time reduction is an important consideration for transit operators interested in operating efficiency and schedule adherence. Travel time reduction is important to transit riders because it can potentially decrease invehicle and out-of-vehicle travel time. Results from deployments and simulation indicate that the degree of transit travel time reduction is a function of the type and combination of transit signal priority strategy used.

Transit travel time reduction can be described by triangular fuzzy numbers (Teodorovic and Kikuchi 1991). Triangular fuzzy numbers represent a special set of fuzzy numbers. Their name is derived from the shape of their membership function. Figure 5 shows the triangular fuzzy number $A=\left(a_{1}, a_{2}, a_{3}\right)$ where $a_{1}$ is the lower (left) boundary of the triangular fuzzy number, $a_{2}$ is the number corresponding to the highest level of presumption, and $a_{3}$ is the upper (right) boundary of the triangular fuzzy number.

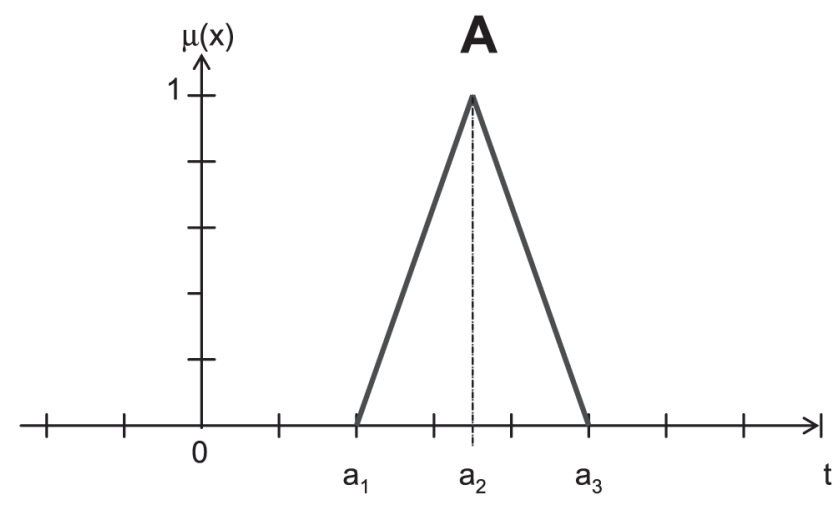

\section{Figure 5. Membership Function of Fuzzy Set A}

The base of the triangular fuzzy number $A,\left(a_{1}\right.$ and $\left.a_{3}\right)$ in Figure 5 , is used to represent the confidence interval range of the transit travel time reduction, and a2 denotes the approximate mean. The triangular fuzzy number representing a transit travel time reduction of $2 \%-4 \%$ would have $a_{1}=2 \%, a_{2}=3 \%$, and $a_{3}=4 \%$. 
Fuzzifying Nontransit Delay Performance Data. The potential impact of transit signal priority on nontransit delay is of considerable concern among all the stakeholders (Gifford et al. 2001). Results from deployments and simulations indicate that nontransit vehicles along the priority route generally benefit from transit signal priority while nontransit vehicles on cross streets experience some increased delay (Chada 2004). Researchers have found that the degree of nontransit delay is strongly related to the volume/capacity $(\mathrm{v} / \mathrm{c})$ ratios of both the approach and cross streets. Approach $\mathrm{v} / \mathrm{c}$ ratios between approximately 0.20 and 0.90 are best suited for transit signal priority applications. Cross-street performance impacts are minimal at low cross-street $\mathrm{v} / \mathrm{c}$ ratios $(0.25 \leq \mathrm{v} / \mathrm{c} \leq 0.5)$, moderate at cross-street $\mathrm{v} / \mathrm{c}$ ratios of 0.8 , and significant at cross-street $\mathrm{v} / \mathrm{c}$ ratios above 0.9 (Ngan 2003). The membership function that linguistically represents the impact on cross-street performance across the entire range of $\mathrm{v} / \mathrm{c}$ ratios is shown in Figure $6 \mathrm{a}$. Figure $6 \mathrm{~b}$ represents the conversion scale to translate the linguistic terms of Figure 6a. Using Figures $6 \mathrm{a}$ and $6 \mathrm{~b}$, a cross-street $\mathrm{v} / \mathrm{c}$ ratio of 0.6 (moderate impact) is converted to a triangular fuzzy number of $(0,5,10)$.

Fuzzifying Schedule Reliability. Transit signal priority has the potential to improve bus schedule reliability. The notion of schedule reliability, also referred to as schedule adherence, is simply to get buses to arrive at bus stops on schedule (i.e., within a certain threshold range). Several different measures of effectiveness have been identified. These performance measures include: on-time performance, time reliability, perceived on-time performance, spacing, and arrival reliability (Chang et al. 2002). Arrival time reliability measures the deviation of actual arrival times versus scheduled arrival times and is useful because the majority of transit passengers go to work usually at the same time each day and rely on consistent arrival schedule windows to arrive at work on time.

The intersection of fuzzy sets is used to assess the value of a set of arrival times in relation to the acceptable threshold. The membership function of fuzzy set $\mathbf{A}$, shown in Figure 7, represents an acceptable threshold between 1.5 minutes early and 4 minutes late. The fuzzy sets $\mathbf{B}_{1^{\prime}} \mathbf{B}_{2^{\prime}}$, represent the arrival times approximately 1 minute late and approximately 3 minutes late, respectively. The shaded area represents the intersection of these arrival times to the acceptable arrival time threshold. The truth values ( 0.8 and 0.38 ) correspond to the highest membership of the intersection of $\mathbf{B}_{1}$, and $\mathbf{B}_{2}$ to $\mathbf{A}$ and uniquely define the performance of these two arrival times with respect to the threshold range. 


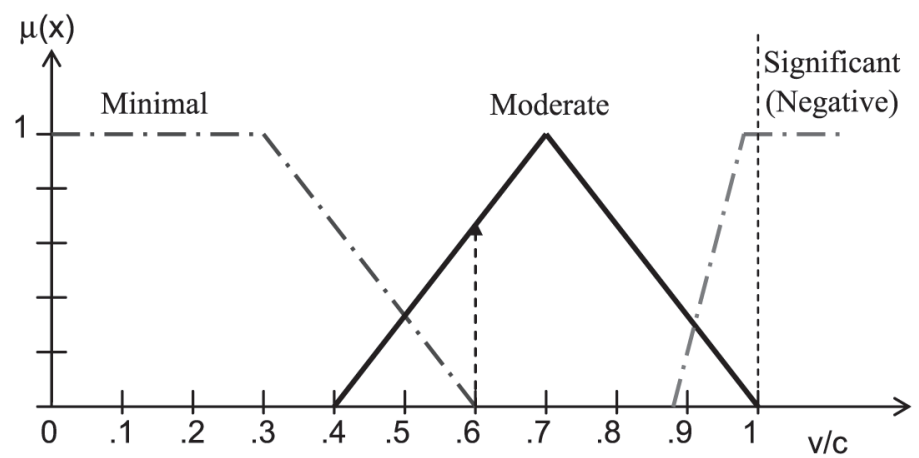

6a. Membership Function for Nontransit Delay

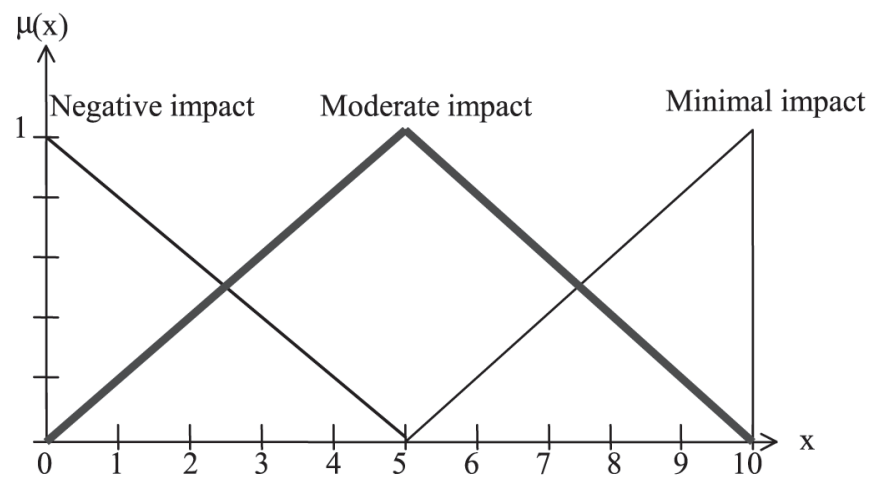

6b. Membership Function for "Negative Impact,"

"Moderate Impact", "Minimal Impact"

\section{Figure 6. Fuzzifying Nontransit Delay}

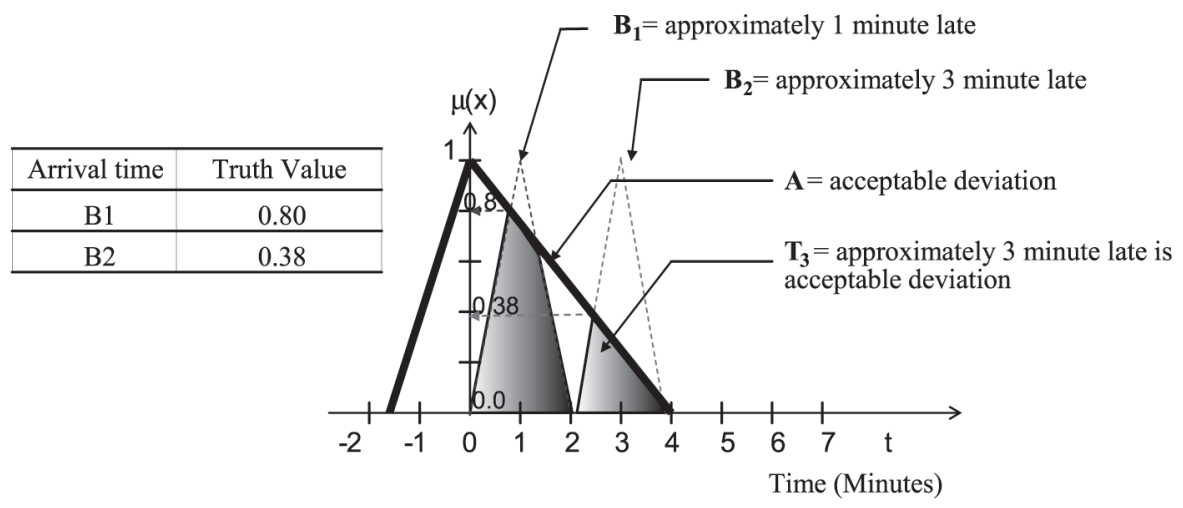

Figure 7. Fuzzifying Schedule Reliability 
Fuzzifying Stakeholder Concerns. Stakeholder objectives, needs, and preferences are important considerations. Potential stakeholders include elected officials, traffic representatives, transit representatives, fire and rescue providers, and transit riders.

Researchers have found that there is a general lack of knowledge and understanding of priority systems on the part of the traffic and transit officials and the public (Noyce 1996; Chada 2004). Results from interviews with stakeholders indicate that while there is significant interest in signal priority and preemption, it is not top priority among elected officials, traffic or transit agencies. In general, stakeholder concerns regarding implementation of transit signal priority are centered about system costs and traffic disruptions, schedule adherence, impact on ridership, and interoperability (Gifford et al. 2001).

Linguistic variables "not important," "important," and "very important" (Figure 4) will be used to represent stakeholder preferences to the three criteria of transit travel time reduction, nontransit delay, and schedule reliability. The triangular fuzzy numbers for these linguistic variables are: $(0,0,5),(0,5,10)$, and $(5,10,10)$, respectively.

Illustrative Example. The following example applies the concepts previously presented to rank order four transit signal priority strategy alternatives based on alternative performance attributes (criteria) and stakeholder preferences. The technical approach is to solve a multiattribute problem that involves a set of $\mathrm{m}$ alternatives $\mathbf{A}_{i}(i=1,2, \ldots, m)$. These alternatives are to be evaluated with respect to $n$ criteria (or attributes) $\mathbf{C}_{\mathbf{j}}(\mathrm{j}=1,2, \ldots, n)$. The weighting vector, $\mathbf{W}$, will represent the relative importance of the criteria to the stakeholders. The decision objective is to rank order all the alternatives in terms of their overall preference value.

1. Determine the alternatives and relevant criteria to be evaluated.

Transit travel time reduction:

$\left(A_{1}\right)$ signal optimization $2 \%-5 \%$

$\left(A_{2}\right)$ green extension $0 \%-9.7 \%$

$\left(A_{3}\right)$ green extension and red truncation $1.4 \%-20 \%$

$\left(A_{4}\right)$ green extension, red truncation, and queue jump $\quad 0 \%-18 \%$

The approach volume capacity ratio is between 0.5 and 0.8 , and the cross-street volume capacity ratio is 0.6 . 
The acceptable arrival threshold is 1 minute early and 5 minutes late. The approximate arrival times for the four alternatives are

$\left(A_{1}\right)$ signal optimization

$\left(A_{2}\right)$ green extension

$\left(\mathrm{A}_{3}\right)$ green extension and red truncation

$\left(\mathrm{A}_{4}\right)$ green extension, red truncation, and queue jump approx. 2 min. late approx. $1.5 \mathrm{~min}$. late approx. $1 \mathrm{~min}$. late approx $.0 .5 \mathrm{~min}$. late

2. Identify relevant participants in the decision process. Relevant stakeholders include elected officials, traffic representatives, transit representatives, emergency service providers, and transit riders. Their concerns and preferences with regard to the three criteria are shown in Table 2.

Table 2. Stakeholder Preferences

\begin{tabular}{|l|l|l|l|}
\hline & $\begin{array}{l}\text { Transit Travel } \\
\text { Time Reduction }\end{array}$ & $\begin{array}{l}\text { Nontransit } \\
\text { Delay }\end{array}$ & $\begin{array}{l}\text { Service } \\
\text { Reliability }\end{array}$ \\
\hline Elected officials & Very Important & Very Important & Very Important \\
Traffic Representatives & Not Important & Very Important & Important \\
Transit Representatives & Very Important & Important & Very Important \\
Emergency Service Providers & Not Important & Important & Not Important \\
Transit Riders & Very Important & Not Important & Very Important \\
\hline
\end{tabular}

3. Convert alternative performance measures to fuzzy numbers. Using the techniques previously described, the alternative performance measures are converted to triangular fuzzy numbers and arrayed in the form a decision matrix (Figure 8).

C1

Transit travel time reduction
$\mathrm{C} 2$

Nontransit delay

Service reliability

$\left.\begin{array}{llll}(2.00,3.50,5.00) & (5.00,10.00,5.00) & (0.70,0.70,0.70) \\ (0.00,4.90,9.00) & (0.00,5.00,10.00) & (0.77,0.77,0.77) \\ (1.40,10.70,20.00) & (0.00,5.00,10.00) & (0.85,0.85,0.85) \\ (0.00,9.00,18.00) & (0.00,5.00,10.00) & (0.93,0.93,0.93)\end{array}\right]$

$\mathrm{A}_{1}$ (Signal optimization)
$\mathrm{A}_{2}$ (Green extension)
$\begin{aligned} & \mathrm{A}_{3} \text { (Green extension \& red } \\ & \text { truncation) }\end{aligned}$
$\begin{aligned} & \mathrm{A}_{4} \text { (Green extension \& red } \\ & \text { truncation \& queue jump) }\end{aligned}$$\quad\left[\begin{array}{lllll}(2.00,3.50, & 5.00) & (5.00,10.00,5.00) & (0.70,0.70,0.70) \\ (0.00,4.90, & 9.00) & (0.00,5.00,10.00) & (0.77,0.77,0.77) \\ (1.40,10.70,20.00) & (0.00,5.00,10.00) & (0.85,0.85,0.85) \\ (0.00,9.00,18.00) & (0.00,5.00,10.00) & (0.93,0.93,0.93)\end{array}\right]$

Figure 8. Decision Matrix 
4. Generate stakeholder preference-based criteria weights. Stakeholder preference for each criterion is determined using Table 2 and Figure 4 (see Table 3).

Table 3. Stakeholder Preference-Based Criteria Weights

\begin{tabular}{|lccc|}
\hline & \multicolumn{1}{c}{$\mathrm{C} 1$} & $\mathrm{C} 2$ & $\mathrm{C} 3$ \\
& $\begin{array}{c}\text { Transit travel } \\
\text { time reduction }\end{array}$ & $\begin{array}{c}\text { Nontransit } \\
\text { delay }\end{array}$ & $\begin{array}{c}\text { Service } \\
\text { reliability }\end{array}$ \\
Elected officials & $(0,5,10)$ & $(5,10,10)$ & $(5,10,10)$ \\
Traffic representatives & $(0,5,10)$ & $(5,10,10)$ & $(0,5,10)$ \\
Transit representatives & $(5,10,10)$ & $(0,5,10)$ & $(5,10,10)$ \\
Emergency service providers & $(0,5,10)$ & $(0,5,10)$ & $(0,0,5)$ \\
Transit riders & $(5,10,10)$ & $(0,0,5)$ & $(5,10,10)$ \\
\hline Average & $(2,7,10)$ & $(2,6,8)$ & $(3,7,9)$ \\
Normalized weight & $(0.10,0.35,0.50)$ & $(0.10,0.30,0.45)$ & $(0.15,0.39,0.45)$ \\
\hline
\end{tabular}

5. Rank the alternatives using multiattribute decision-making methods. The results of steps 3 and 4 are shown in the normalized decision matrix presented in Figure 9.

$$
\begin{array}{lll}
\mathrm{C}_{1} & \mathrm{C}_{2} & \mathrm{C}_{3}
\end{array}
$$

$$
\mathbf{D}=\quad \begin{aligned}
& \mathbf{A}_{1} \\
& \mathbf{A}_{2} \\
& \mathbf{A}_{3} \\
& \mathbf{A}_{4}
\end{aligned}\left[\begin{array}{llll}
(0.10,0.35,0.50) & (0.10,0.30,0.45) & (0.15,0.35,0.45) \\
(0.00,2.45,4.75,2.50) & (5.00,10.00,10.00) & (7.00,7.00,7.00) \\
(0.70,5.35,10.00) & (0.00,5.00,5.00,10.00) & (7.70,7.70,7.70) \\
(0.00,4.50,9.00) & (0.00,5.00,10.00) & (9.30,9.30,9.30)
\end{array}\right]
$$

Figure 9. Normalized Decision Matrix

The alternatives can be ranked ordered using WSM or TOPSIS. For this example, sensitivity analysis and computational experiments indicated that TOPSIS was more responsive to stakeholder preference. Results indicate that $\mathbf{A}_{1}$ (signal optimization) was the preferred alternative when the majority of stakeholders did not consider transit travel time reduction important, and $\mathbf{A}_{\mathbf{3}}$ (green extension and red truncation) was the preferred alternative when the majority of stakeholders considered transit travel time reduction important. 


\section{Summary and Recommendations}

The conceptual DSS framework and three analytical tools presented outline a systematic technique to perform analytical assessments of integrated emergency vehicle preemption and transit signal priority system impacts. These tools use cost factors, accident reduction factors, and soft computing techniques to transform quantitative and qualitative performance data for input into mathematical modeling methods commonly used to support decision making.

Recommendations for future work include:

1. Develop analytical tools to address the potential impact of reduced emergency vehicle travel time on saving lives, reducing injury, reducing property damage, and assessing system level impacts.

2. Expand the fuzzy MADM framework to include other criteria such as investment costs and safety. Cost data may include, for example, infrastructure costs to modify an intersection to accommodate a queue jump or to relocate bus stops from near side to far side to accommodate a green extension. Safety impacts include both transit and pedestrian safety.

3. Link a series of intersections and use dynamic programming to determine the best mix of transit signal priority strategy alternatives along a corridor.

4. Apply fuzzy MADM methods to analyze the performance of integrated signal control systems with various priority strategies.

5. Expand the application of fuzzy MADM methods to other branches of transportation and traffic engineering such as transportation safety analysis where recommendations for safety improvements must consider multiple criteria (e.g., geometric designs, traffic control devices, rules enforcement, infrastructure maintenance, driver behavior and qualification, pedestrian and bicycle traffic, and population demographics) and often require expert knowledge to interpret.

\section{Acknowledgments}

The authors acknowledge support of the Washington Regional Council of Governments, the Virginia Department of Transportation, and the Maryland Department of Transportation for this research. The authors wish to thank Professor Antoine Hobeika, Professor Kostas Triantis, and Dr. Sam Tignor, Virginia Polytechnic Institute and State University, and Professor Jonathan Gifford, George Mason Univer- 
sity, for their guidance and advice on this research. The authors also wish to thank the anonymous reviewers of the Journal of Public Transportation for their helpful comments.

\section{References}

Bullock, D., J. M. Morales, and B. J. Sanderson. 1999. Impact of signal preemption on the operation of the Virginia Route 7 corridor. ITS America.

Chada, S. 2004. Critical factors for transit signal priority. CD-ROM. Washington, DC: Transportation Research Board National Research Council.

Chang, J., J. Collura, F. Dion, H. Rakha. 2002. "Evaluation of service reliability impacts on traffic signal priority strategies for bus transit". Annual Meeting of the Transportation Research Board. National Research Council, Washington, DC.

Chang, J., ed. 2002. An overview of transit signal priority. Washington, DC: ITS America.

Chen, S. J., and C. L. Hwang. 1992. "Fuzzy multiple attribute decision making: Methods and applications". Lecture Notes in Economics and Mathematical Systems 375. Berlin: Springer-Verlag.

Collura, J., H. Rakha, and J. Gifford. 2003. Guidelines for the planning and deployment of emergency vehicle preemption and transit strategies. Washington, DC: Virginia Tech Transportation Institute and George Mason University School of Public Policy.

ECONWest and Parsons Brinckerhoff Quade \& Douglas. 2002. TCRP Report 78 Estimating the benefits and costs of public transit projects: A guidebook for practitioners. Washington, DC: Transit Cooperative Research Program.

Gifford, J., D. Pelletiere, and J. Collura. 2001. Stakeholder requirements for traffic signal preemption and priority in the Washington, D.C., region. Journal of the Transportation Research Board 1748: 1-7.

Gkritza, K., J. Collura, S. Tignor, D. Teodorovic. 2004. An analysis of the characteristics of emergency vehicle operations in the Washington D.C. region. CD-ROM. Washington, DC: Transportation Research Board National Research Council. 
Lee, D., and A. Carroll. 2001. Benefit-cost evaluation of a highway-railroad intermodal control system. Cambridge, MA:U.S. Department of Transportation, Volpe National Transportation Systems Center.

Levine, J., S. Park, S. Underwood, and R. Wallace. 1999. Stakeholder preferences in advanced transportation system planning. Journal of Public Transportation 2(1): 25-45.

Morlok, E. K., E. C. Brunn, and K. J. Blackman. 1991. Advanced vehicle monitoring and communication systems for bus transit: Benefits and economic feasibility. Washington, DC: University Research and Training Program, Office of Technical Assistance, Federal Transit Administration.

Ngan, V. 2003. A comprehensive strategy for transit signal priority. ITE Journal (November): 28-32.

Noyce, D. A. 1996. Barriers to implementation of signal priority systems for transit operations: Lessons learned from advanced traffic management systems. College Station, TX: Department of Civil Engineering, Texas A\&M University.

Soo, H., J. Collura, A. Hobeika, and D. Teodorovic. 2004. An analytical frameworkfor evaluating the impacts of advanced traffic signal control systems for emergency vehicle preemption and transit priority. CD-ROM, ITS America's 14th Annual Meeting and Exhibition.

Soo, H., J. Collura, and D. Teodorovic. 2005. Towards the development of an advanced traffic signal control system for advanced traffic signal control systems investment planning. CD-ROM, Transportation Research Board Annual Meeting.

Teodorovic, D. 1994. Fuzzy sets theory applications in traffic and transportation. European Journal of Operational Research 74: 379-390.

Teodorovic, D., and S. Kikuchi. 1991. Application of fuzzy sets theory to the saving based vehicle routing algorithm. Civil Engineering Systems 8: 87-93.

\section{About the Authors}

Houng Soo (hsoo@vt.edu) has more than 25 years of experience in engineering and engineering management with the U.S. Army Corps of Engineers. Over the last four years he has been involved in research relating to economic evaluations of Intelligent Transportation Systems with an emphasis on emergency vehicle pre- 
emption and transit signal priority as a graduate research associate at the Virginia Polytechnic Institute and State University. Dr. Soo received his Ph.D. in civil engineering (transportation) from the Virginia Polytechnic Institute and State University, his MBA from Florida Institute of Technology, his M.S. (nuclear engineering) from the University of Washington, and his BSEE from Polytechnic Institute of Brooklyn. Dr. Soo is also a registered professional engineer.

John ColluRA (jcollura@umass.edu) is a professor of civil engineering at the University of Massachusetts. Dr. Collura has more than 25 years of experience in transportation research and education with an emphasis on public transportation planning, management, and performance evaluation, and the application of information-based technologies. He also teaches courses in public transit design and operations, and in public transit planning and analysis. Dr. Collura received his Ph.D. in civil engineering (transportation) from the North Carolina State University, his MSCE (transportation) from Villanova University, and his BSCE from Merrimack College. Dr. Collura is also a registered professional engineer.

Dusan TeOdorovic (duteodor@vt.edu) is a Professor Emeritus in the Department of Civil and Environmental Engineering at the Virginia Polytechnic Institute and State University. He received his B.S., M.S. and Ph.D. degrees in transportation engineering at the University of Belgrade. Dr. Teodorovic has more than 25 years experience in transportation research and education. His areas of emphasis include: transportation planning, transportation networks, transportation modeling, air transportation, operations research, and fuzzy and neuro modeling. He is published widely in international journals and has served as professor of transportation engineering and operations research at the University of Belgrade; as visiting professor in the Department of Civil Engineering at the Technical University of Denmark; Operations Research Program at the University of Delaware; and National Chiao Tung University, Taiwan. 